Published in final edited form as:

J Acad Nutr Diet. 2015 May ; 115(5): 731-742. doi:10.1016/j.jand.2014.11.003.

\title{
Partial meal replacement plan and quality of the diet at one year: Action for Health in Diabetes (Look AHEAD) Trial
}

\author{
Hollie A. Raynor, Ph.D., R.D., \\ Associate Professor, Department of Nutrition, University of Tennessee; 1215.W. Cumberland \\ Ave, JHB 229, Knoxville, TN 37996; p: 865-974-6259; f: 865-974-3491
}

\author{
Andrea M. Anderson, M.S, \\ Biostatistician, Department of Biostatistical Sciences, Wake Forest University School of Medicine; \\ Medical Center Blvd, Winston-Salem, NC 27157; p: 336-713-5174; f: 336-713-5308 \\ Gary D. Miller, Ph.D., R.D., \\ Associate Professor, Department of Health and Exercise Science, Wake Forest University; Box \\ 7868 Winston-Salem, NC 27109; p: 336-758-1901; f: 3369-758-4680 \\ Rebecca Reeves, Ph.D., R.D., \\ Adjunct Assistant Professor, The University of Texas School of Public Health Austin Regional \\ Campus, 1616 Guadalupe, Suite 6.300, Austin, TX 78701; p: 512-482-6160

\section{Linda M. Delahanty, M.S., R.D., \\ Director of Nutrition and Behavioral Research, Massachusetts General Hospital Diabetes Center and Instructor, Harvard Medical School; Boston, MA 02114; p: 617-724-9727; f: 617-726-1871}

\section{Mara Z. Vitolins, Dr. P.H., M.P.H., R.D.,}

Professor and Vice Chair, Department of Epidemiology and Prevention, Wake Forest School of Medicine; Medical Center Boulevard, Winston-Salem, NC 27157; p: 336-716-2886; f: 336-713-4300

Patricia Harper, M.S., R.D., P. Harper \& Associates, 2460 Robbins Station Road, North Huntingdon, PA 15642; p: 412-751-4498

Connie Mobley, Ph.D., R.D.,

\footnotetext{
(C) 2014 by the Academy of Nutrition and Dietetics. All rights reserved.

Corresponding author and requests for reprints: Hollie A. Raynor, Ph.D., R.D.; Associate Professor, Department of Nutrition, University of Tennessee; 1215.W. Cumberland Ave, JHB 229, Knoxville, TN 37996; p: 865-974-6259; f: 865-974-3491; hraynor@utk.edu.

All other Look AHEAD staffs are listed alphabetically by site.

Conflict of Interest Statement

HR has research funding from Weight Watchers, International. All other authors declare no conflicts of interest.

Publisher's Disclaimer: This is a PDF file of an unedited manuscript that has been accepted for publication. As a service to our customers we are providing this early version of the manuscript. The manuscript will undergo copyediting, typesetting, and review of the resulting proof before it is published in its final citable form. Please note that during the production process errors may be discovered which could affect the content, and all legal disclaimers that apply to the journal pertain.
} 
Associate Dean of Research and Professor, Department ofBiomedical Studies, School of Dental Medicine, University of Nevada Las Vegas; 1001 Shadow Lane, MS 7424, Las Vegas, NV 89106-4124; p: 702-774-2643; f: 702-774-2647

Kati Konersman, M.A., Project Coordinator, Baylor University Medical Center, Diabetes Health and Wellness Institute, 4500 Spring Ave. Dallas, TX 75210; p: 214-915-3282

Elizabeth Mayer-Davis, Ph.D., R.D., and

Professor, Department of Nutrition, University of North Carolina at Chapel Hill; 2211 McGavranGreenberg Hall, 135 Dauer Drive, Campus Box 7461, Chapel Hill, NC 27599; p: 919-966-1991

\section{the Look AHEAD Research Group}

Hollie A. Raynor: hraynor@utk.edu; Andrea M. Anderson: amanders@wakehealth.edu; Gary D. Miller: millergd@wfu.edu; Rebecca Reeves: rebeccasreeves@hughandbecky.com; Linda M. Delahanty: Idelahanty@partners.org; Mara Z. Vitolins: mvitolin@wakehealth.edu; Patricia Harper: pathharper@gmail.com; Connie Mobley: connie.mobley@unlv.edu; Kati Konersman: kati.konersman@baylorhealth.edu; Elizabeth Mayer-Davis: mayerdav@email.unc.edu

\section{Abstract}

Background-Little is known about diet quality with a reduced-energy, low-fat, partial meal replacement (PMR) plan, especially in individuals with type 2 diabetes. The Action for Health in Diabetes (Look AHEAD) trial implemented a PMR plan in the intensive lifestyle intervention (ILI).

Objective-Compare dietary intake and percent meeting fat-related and food group dietary recommendations in ILI and diabetes support and education (DSE) groups at 12 months.

Design-Randomized controlled trial, comparing ILI to DSE, at 0- and 12-months.

Participants/setting-From 16 United States sites, the first 50\% of participants (aged 45 to 76 years, overweight or obese, with type 2 diabetes) were invited to complete dietary assessments. Complete 0- and 12-month dietary assessments (collected between 2001 and 2004) were available on 2,397 participants (46.6\% of total participants), with 1,186 randomized to DSE and 1,211 randomized to ILI.

Main outcome measures-A food frequency questionnaire assessed intake: energy; percent energy from protein, fat, carbohydrate, polyunsaturated fatty acids (PUFA), and saturated fats; trans fatty acids; cholesterol; fiber; weekly meal replacements (MRs); and daily servings from food groups from the Food Guide Pyramid.

Statistical analyses performed-Mixed-factor analyses of covariance (ANCOVA), using Proc MIXED with a repeated statement, with age, sex, race/ethnicity, education, and income controlled. Unadjusted chi-square tests compared percent meeting fat-related and food group recommendations at 12 months.

Results-At 12 months, ILI had a significantly lower fat and cholesterol intake and greater fiber intake than DSE. ILI consumed more servings/day of fruits; vegetables; and milk, yogurt \& cheese; and fewer servings/day of fats, oils \& sweets than DSE. A greater percentage of ILI than DSE participants met fat-related and most food group recommendations. Within ILI, a greater percentage of participants consuming $\geq 2 \mathrm{MRs} /$ day than $<1 \mathrm{MR} /$ day met most fat-related and food group recommendations. 
Conclusions-The PMR plan consumed by ILI was related to superior diet quality.

\section{Keywords}

Partial meal replacement plan; diet quality; Type 2 diabetes; lifestyle intervention

A partial meal replacement (PMR) plan contains two portioned-controlled, vitamin/mineral fortified meal replacements (MRs), usually beverages and food bars, per day and one balanced meal consisting of lower-energy, high-nutrient-dense, conventional foods. ${ }^{1}$ While a PMR plan has been found to be an efficacious strategy for weight loss, ${ }^{1}$ little is known about how a reduced-energy, low-fat, PMR plan influences diet quality, particularly in regards to meeting Dietary Guideline recommendations. ${ }^{2}$ Only three investigations have examined macro- and micronutrient intake of healthy obese older adults ${ }^{3}$ and healthy overweight and obese women ${ }^{4,5}$ prescribed a reduced-energy, low-fat, PMR plan. One investigation found lower total and saturated fat intake with the PMR plan in comparison to an attention control group, ${ }^{3}$ one investigation found lower total fat and cholesterol intake with the PMR plan in comparison to a reduced-energy, low-fat diet comprised of conventional foods, ${ }^{5}$ while all studies found greater key micronutrient intake (i.e., calcium, vitamin $\mathrm{D}$, vitamin $\mathrm{E}$, and Vitamin C) in the PMR plan as compared to either an attention control group ${ }^{3}$ or a reduced-energy, low-fat diet comprised of conventional foods. ${ }^{4,5}$ None of the studies examined overall food group intake or the percentage of participants meeting recommendations for food group intake when prescribed a reduced-energy, low-fat, PMR plan. Additionally, while diet quality of a PMR plan has been examined in healthy overweight and obese individuals, diet quality of a PMR plan has not been examined in individuals with type 2 diabetes.

The Action for Health in Diabetes (Look AHEAD) trial is a 16 center, randomized controlled trial, whose purpose was to investigate the influence of weight loss achieved via an intensive lifestyle intervention (ILI) on long-term cardiovascular health in overweight or obese adults with type 2 diabetes. There are two study arms in Look AHEAD: ILI, which focuses on weight loss through a lifestyle intervention, and a diabetes support and education (DSE) group that provides education on nutrition and physical activity and social support to participants. ${ }^{6,7}$ The 12-month changes in weight indicated that participants in ILI lost a significantly greater amount of their initial body weight than those in DSE $(-8.6 \% \pm 6.9 \%$ vs. $-0.7 \% \pm 4.8 \%) .{ }^{8}$ To achieve weight loss, ILI was prescribed a reduced-energy, low-fat diet, PMR plan. Thus, Look AHEAD provides an opportunity to examine diet quality in patients with type 2 diabetes consuming a PMR plan.

Therefore the aim of this investigation was to investigate diet changes in the ILI and DSE groups from 0 - to 12 -months and to examine diet quality at 12 months between the two groups. Furthermore within the ILI group, diet quality was examined in participants who self-reported consumption of meal replacements $<1,1$ to $<2$, or $\geq 2 \mathrm{MRs} /$ day. Measures of diet quality included macronutrient and Food Guide Pyramid (FGP) ${ }^{9}$ food group intake. Percentage of participants at 12 months meeting fat, cholesterol, and minimum daily food FGP group serving recommendations of the 2000 Dietary Guidelines for Americans ${ }^{2}$ in each group, and in ILI by MR consumption category, was examined. These recommended 
guidelines were used in this investigation as these were the guidelines in place during the first year of the Look AHEAD trial. Due to the previous findings related to macro- and micronutrient intake when a reduced-energy, low-fat, PMR is consumed, it was hypothesized that at 12 months, ILI would have a greater percentage of participants meeting fat-related and food group intake recommendations than DSE, and that in the ILI, a greater percentage of participants consuming $\geq 2 \mathrm{MRs} /$ day as compared to the percentage of participants consuming $<1 \mathrm{MR} /$ day would report meeting these same recommendations.

\section{Methods}

\section{Research Design and Participants}

Participants were recruited for Look AHEAD over 2.5 years beginning in 2001. ${ }^{7}$ Look AHEAD randomized 5,145 participants with type 2 diabetes aged 45-76 years (the age range was changed to 55-76 years in the second year of recruitment to increase the rate of anticipated cardiovascular events) with a body mass index (BMI) $\geq 25 \mathrm{~kg} / \mathrm{m}^{2}\left(\geq 27 \mathrm{~kg} / \mathrm{m}^{2}\right.$ if taking insulin) and no upper limit for BMI. ${ }^{7}$ The goal of recruitment was to achieve equal numbers of men and women and a minimum of $33 \%$ of participants from racial/ethnic minority groups and to have $\$ 30 \%$ of participants taking insulin. ${ }^{7}$ Exclusion criteria included inadequate control of diabetes (i.e., A1C $>11 \%$ ), factors affecting a participant's ability to adhere to interventions, and underlying diseases likely to limit life span and/or affect the safety of the interventions. ${ }^{7}$ Eligibility for Look AHEAD was determined using a series of screening visits. Additionally, potential participants completed a two-week run-in, in which food intake and physical activity was recorded for two weeks. Those potential participants who did not keep satisfactory records for at least 12 of 14 days were considered ineligible. All participants gave informed consent, consistent with the Helsinki Declaration and approved by the institutional review board of each center.

For this investigation, participants who completed the dietary assessment component of the trial at 0 and 12 months were included. At each site, the first 50\% of participants assessed were asked to complete dietary assessments. At baseline, 2,973 dietary assessments were completed prior to randomization. Of the 2,397 with 0 - and 12-month assessments, 1,186 (49.5\%) were randomized to DSE and 1,211 (50.5\%) were randomized to ILI. Participants were provided $\$ 100$ for completion of the 12-month follow-up.

\section{Interventions}

Following completion of baseline measures, participants were randomized to ILI or DSE. For ILI, in the first six months of the program participants were prescribed a low-energy (1200 to $1500 \mathrm{kcal} /$ day for those < $113.6 \mathrm{~kg}$, and 1500 to $1800 \mathrm{kcal} /$ day for those $\geq 113.6$ $\mathrm{kg})$, low-fat $\left(<30 \% \mathrm{kcal}\right.$ from fat, with $<10 \%$ from saturated fat) diet. $^{6}$ The ILI prescription also included a PMR plan, in which for the first four months (weeks 3-19 of the trial), MRs (beverages and food bars) were recommended to be consumed to replace two meals per day and one or two snacks per day. ${ }^{10}$ The MRs were provided to participants. One meal was to be consumed from conventional foods, with an emphasis of adding fruits and vegetables to the diet. ${ }^{6}$ Starting week 20 until completion of the first year of the trial, participants were encouraged to replace one or two meals and snacks per day with MRs, with only one MR 
per day provided to participants. ${ }^{10}$ Participants who refused MRs were provided detailed menu plans that specified amounts of conventional foods to be consumed. ${ }^{6}$ ILI also received a physical activity goal of 175 minutes of moderate-intensity physical activity per week. During the first six months of the program participants in the ILI attended three group sessions per month, in which lifestyle modification topics and techniques were presented, and received one individual session per month. ${ }^{6,7}$ During months 7 to 12 , participants received two group sessions and one individual session per month. ${ }^{6,7}$ Participants in ILI self-monitored their energy and fat gram intake daily via a food diary. Diaries were reviewed by intervention staff, which included registered dietitians, so that feedback could be provided to participants to assist them in meeting the dietary prescription.

If participants in the ILI were unsuccessful at meeting diet and physical activity goals and thus had lower weight loss than expected, a toolbox approach was implemented to assist these participants in meeting goals. ${ }^{6}$ The toolbox was composed of advanced behavioral strategies (i.e., provision of exercise equipment, enrolling participants in a supervised exercise program or a cooking class, etc.) and the weight loss medication orlistat. Selection of a particular strategy was individualized and designed to address the barriers experienced by the participant, using a series of algorithms. Use of orlistat was closely monitored. When using orlistat, it is recommended that foods high in fat are avoided. Orlistat was offered as an option to participants if after the first six months they had lost $<5 \%$ or $\geq 5 \%$ but $<10 \%$ of initial weight. Additionally, participants who had lost $\geq 10 \%$ of initial weight but after six months had regained $\geq 2 \%$ were offered the option of using orlistat. Participants who took orlistat were monitored by a study physician or nurse practitioner.

The DSE group received general information on dietary intake and physical activity via three group sessions per year. ${ }^{7}$ The DSE group received no counseling regarding behavior modification for changing dietary intake, increasing physical activity, or losing weight. ${ }^{7}$

\section{Measures}

\section{Sociodemographic and anthropometric characteristics-Self-reported}

information on age, sex, race/ethnicity, highest level of education, and annual household income was collected from participants. BMI was calculated as body weight in kilograms divided by the square of height in meters, with height measured by a wall-mounted stadiometer (Seca 214, Seca North America East, Hanover, MD) and weight measured by electronic scale (Tanita, model BWB-800, Willobrook, IL). Both measures were performed with outer garments (coats, jackets, sweaters) removed and without shoes.

Dietary assessment-For the Look AHEAD Trial, a semi-quantitative, food frequency questionnaire (FFQ) was utilized to assess dietary intake. This FFQ was a modified version of the Diabetes Prevention Program (DPP) FFQ ${ }^{11-13}$ and measured usual intake over the previous six months. The DPP food list, designed to enhance sensitivity to regional and ethnic food choices, ${ }^{12}$ served as a basis of the food list in the Look AHEAD FFQ. The FFQ contained 134 line items, 20 items that can be used to adjust the 134 main items (i.e., type of oil used when cooking, fat added to vegetables, etc.), and three quality control questions. As 
the ILI prescribed the use of MRs, MR beverages and food bars were added as line items to the FFQ.

For each line item, respondents reported their frequency of consumption and portion size consumed. The nine frequency categories for food items ranged from "never or less than once per month" to " 2 or more times per day." The nine frequency categories for beverages ranged from "never or less than once per month" to " 6 or more times per day." Portion sizes were listed as small, medium, or large.

Participants responded to additional questions about how frequently they consumed low-fat versions of 10 foods: meat, bacon/sausage, burritos, cookies/cake, cheese, snack, lunch meats, pizza, spaghetti, and yogurt. Frequency categories were: "I do not eat the foods," "seldom/never," "sometimes," and "often/always."

Participants were provided instructions on how to complete the FFQ. Following its completion, the questionnaire was reviewed by a staff member, blinded to randomization, for errors and completeness.

Management of the dietary assessment for the Look AHEAD trial was centralized at the Look AHEAD Diet Assessment Center (DAC), located at the University of South Carolina, Columbia, SC. One primary diet interviewer for each site was certified by DAC staff to administer and review the FFQ. Certification of this interviewer was conducted annually. The FFQs were reviewed initially at each site, and additional editing and quality control checks (i.e., internal consistency and range) were performed at the DAC using the edit checks in the National Cancer Institute Health Habits and History Questionnaire HHHQ/ DietSys program (version 3.0, 1993, National Cancer Institute, Rockville, MD), followed by a DAC staff review if a food or nutrient value was found to be extreme.

Daily dietary estimates of food group and nutrient intake were determined using the HHQ/ DietSys software and Look AHEAD specific programming that incorporated the specific Look AHEAD modifications to the FFQ. The nutrient database that was utilized was modified from the DPP database so that foods added to the Look AHEAD FFQ (i.e., MRs) could be incorporated. For MRs, a total of 38 beverages and 86 food bars were identified as consumed by participants. A cluster analyses was conducted and three macronutrient composition clusters, three for beverages and three for food bars, emerged. For beverages the three macronutrient composition clusters were: 1) $13.0 \%$ energy from fat, $70.6 \%$ energy from carbohydrate, and $18.7 \%$ energy from protein; 2) $37.9 \%$ energy from fat, $48.2 \%$ energy from carbohydrate, and $17.3 \%$ energy from protein; and 3) 26.9\% energy from fat, $24.9 \%$ energy from carbohydrate, and $50.1 \%$ energy from protein. For food bars the three macronutrient composition clusters were: 1) $25.5 \%$ energy from fat, $61.4 \%$ energy from carbohydrate, and $16.4 \%$ energy from protein; 2) $14.4 \%$ energy from fat, $75.0 \%$ energy from carbohydrate, and $15.0 \%$ energy from protein; and 3) $26.2 \%$ energy from fat, $40.9 \%$ energy from carbohydrate, and 33.9\% energy from protein. All individual MR's energy (on average each MR was approximately $180 \mathrm{kcal}$ ) and macronutrient composition was coded according to the appropriate cluster. Nutrient values were obtained from the Nutrition Data System (NDS-R) Nutrition Coordinating Center, University of Minnesota, Minneapolis, MN 
(version 4.01_30, 1999). The portion size database (gram weights for small, medium, and large portions based upon sex and age) was also modified to incorporate the new foods on the Look AHEAD FFQ. Food group servings were based upon the FGP, ${ }^{9}$ and MRs were coded as milk, yogurt \& cheese (beverage) and meat, poultry, fish, dry beans, eggs \& nuts (food bars).

Primary dietary variables-Primary dietary variables measured at 0 and 12 months included: energy in kilocalories per day (kcal/day); percent energy from protein, fat, carbohydrate, polyunsaturated fatty acids (PUFA), and saturated fats; trans fatty acids in grams per day (g/day); cholesterol in milligrams per day (mg/day); dietary fiber in grams per day (g/day); and number of weekly MRs consumed. Food group consumption based on the FGP was measured by the number of daily servings at 0 and 12 months.

Additionally, changes in frequency of consumption of low-fat versions of the 10 additional foods listed on the FFQ were examined. Changes in frequency of consumption were calculated as increasing in frequency (changing from seldom/never to sometimes or often/ always, or changing from sometimes to often/always), decreasing in frequency (changing from often/always to sometimes or seldom/never, or changing from sometimes to seldom/ never), or not changing in frequency from 0 to 12 months.

The percentage of participants meeting the following guidelines were calculated for analysis from 12-month data: 1) $\leq 30 \%$ energy from fat; 2) $\leq 10 \%$ energy from saturated fat; and 3) < $300 \mathrm{mg} /$ day of cholesterol. The percentage of participants meeting the minimum recommended number of daily servings from each food group (bread, cereal, rice \& pasta; fruit; vegetable; milk, yogurt \& cheese; meat, poultry, fish, dry beans, eggs \& nuts; and fats, oils \& sweets) from the FGP was also calculated at 12 months. ${ }^{2}$ Finally, participants in the ILI group were divided into one of three groups based upon MR consumption: <1/day, 1 to $<2 /$ day, and $\geq 2$ /day. The percentage of participants in each MR group who met the guidelines at 12 months was assessed.

\section{Statistical Analysis}

Chi-square tests and independent t-tests were used to assess differences in baseline characteristics between excluded and included patients and between the two intervention groups. Several dietary variables, energy, trans fatty acids, fiber, MRs, and daily servings consumed from all food groups, were not normally distributed; thus, log transformations were used to normalize the distribution of these variables. Mixed-factor analyses of covariance (ANCOVA), with a between-subject factor of group (ILI vs. DSE) and withinsubject factor of time ( 0 and 12 months), with age, sex, race/ethnicity, education, and income controlled, using Proc MIXED with a repeated statement, were conducted to examine change in the primary dependent variables of interest. The primary dependent variables examined in these analyses were energy; percent energy from fat, carbohydrate, protein, PUFA, and saturated fat; trans fatty acid; cholesterol; fiber; and weekly MR intake. Similar analyses were performed to determine changes in daily servings consumed from food groups from the FGP. For assessing the consumption of low-fat versions of the 10 additional foods listed on the FFQ, change in frequency of consumption from 0 to 12 
months was categorized as "increased," "decreased," or "no change." Unadjusted chi-square tests were used to assess for differences between ILI and DSE in changes in frequency of consumption of low-fat food items and percentage meeting recommended guidelines, and for ILI differences by MR consumption in percentage meeting recommended guidelines. Differences in least squares means were assessed when the adjusted time by group interactions was significant. Data are reported as mean and standard deviation (SD): mean (SD). All analyses were conducted using SAS v9.1 (Cary, NC), using an alpha level of $\leq$ 0.05 for significance.

\section{Results}

Comparisons were made between Look AHEAD participants with 0- and 12-month data and who had dietary data and thus were included in this investigation $(n=2,397)$ and who did not have dietary data and thus were not included in this investigation $(\mathrm{n}=2,505)$. Significant differences were found in age (included $=57.2$ [7.2] yrs vs. not included $=60.2[6.1] \mathrm{yrs}, \mathrm{p}$ $<0.001$ ), race (included $=13.8 \%$ African-American vs. not included $=17.2 \%$ AfricanAmerican, $\mathrm{p}<0.05$ ) and annual household income (included $=31.5 \%<\$ 40,000$ vs. not included $=35.7 \%<\$ 40,000, \mathrm{p}<0.01)$. Due to the change in age eligibility criteria after the first year, additional analyses were conducted to determine if there were differences in age in those included and those not included in the analyses in the first year and remaining years in which randomization occurred. Independent $t$-tests showed that there was no significant difference in age in the first year (included $[n=1776]=56.3$ [7.2] yrs vs. not included $[\mathrm{n}=252]=56.8$ [7.7] yrs). In the remaining years of randomization, those included in the analyses $(n=618)$ were significantly younger than those not included $(n=2253)(59.6$ [6.5] yrs vs 60.6 [5.8] yrs, $p<0.001$ ). No differences were found in participants included and not included in the investigation in BMI, sex, and education.

Baseline characteristics of the participants included in the analyses are shown in Table 1. Participants were 59.2\% female, 64.8\% non-Hispanic White, with a mean age of 57.2 (7.2) yrs, and a mean BMI of $36.1(6.0) \mathrm{kg} / \mathrm{m}^{2}$. Additionally, $79.5 \%$ had some college education and $39.7 \%$ had a yearly income of $\geq \$ 70,000$. There were no significant differences between the two groups on any of these characteristics ( $p>0.20$ ). During months 7 to 12, 263 $(21.7 \%)$ of participants in ILI used orlistat.

Energy; percent energy from carbohydrate, fat, protein, PUFA, and saturated fat; trans fatty acids; cholesterol; fiber; and weekly MR intake, at 0 and 12 months in the two groups are shown in Table 2. There were no differences at 0 months between the groups on any of these dietary variables. For both energy and percent energy from protein intake, there was a significant main effect of time, with both groups reducing energy intake (ILI: -331 [760] $\mathrm{kcal} /$ day; DSE: -310 [750] kcal/day) and increasing percent energy from protein over time (ILI: +0.9 [3.0] \%; DSE: +0.7 [3.2] \%) (p < 0.0001). All other nutrients showed significant interactions of group $\mathrm{x}$ time $(\mathrm{p}<0.0001)$. For percent energy from fat, saturated fat and PUFA; trans fatty acids; and cholesterol intake, ILI showed greater decreases over time, and at 12 months ILI had a significantly lower intake than DSE ( $p<0.0001$ ). ILI showed a greater increase in percent energy from carbohydrate and dietary fiber intake, as ILI had a significantly greater intake at 12 months than DSE $(\mathrm{p}<0.0001)$. 
MR consumption also demonstrated a significant group $\mathrm{x}$ time interaction $(\mathrm{p}<0.0001)$ (see Table 2). There were no differences in intake between the groups at 0 months, but at 12 months ILI had increased consumption and reported greater weekly intake of MRs than DSE (13.5 [10.7] MRs/week vs. 1.5 [4.1] MRs/week, p < 0.0001).

Consumption of daily servings of food groups from the FGP for ILI and DSE at 0 and 12 months is shown in Table 3. There were no significant differences between the groups in food group intake at month 0 . There was a significant group $\mathrm{x}$ time interaction for daily servings from the bread, cereal, rice \& pasta; fruit; vegetable; milk, yogurt \& cheese; meat, poultry, fish, dry beans, eggs \& nuts; and fats, oils \& sweets groups ( $\mathrm{p}<0.0001)$. ILI showed a decrease over time in consumption of daily servings from the bread, cereal, rice \& pasta; meat, poultry, fish, dry beans, eggs \& nuts; and fats, oils \& sweets groups, and at 12 months, ILI consumed significantly fewer daily servings from these food groups than DSE ( $\mathrm{p}<0.0001)$. Additionally, ILI increased intake of daily servings from the fruit; vegetable; and milk, yogurt \& cheese groups, and at 12 months ILI consumed significantly more daily servings from these food groups than DSE $(\mathrm{p}<0.0001)$.

Change in frequency of consumption of low-fat versions of the additional foods was significant for 9 out of the 10 food items, with ILI reporting a larger percentage of participants increasing their frequency of consumption of the low-fat versions from 0 to 12 months than DSE $(\mathrm{p}<0.01)$ (see Figure 1). The only low-fat version of food that was not significantly different between the two groups was low-fat meat.

Percentage of participants in ILI and DSE meeting recommendations at 12 months is shown in Table 4. A significantly higher percentage of ILI participants than DSE met the guidelines for percent energy from fat and saturated fat, and cholesterol, as well as for the fruit; vegetable; milk, yogurt \& cheese; and fats, oils \& sweets food group intake ( $<$ 0.0001). A significantly greater percentage of DSE participants met the recommendations for bread, cereal, rice \& pasta; and meat, poultry, fish, dry beans, eggs $\&$ nuts food group intake than ILI $(\mathrm{p}<0.0001)$.

Table 5 shows the percentage of participants in the MR categories in the ILI group meeting recommendations at 12 months. There was no difference in percentage of participants in the MR categories using orlistat during months 7 to 12. Except for the recommendations for bread, cereal, rice \& pasta and meat, poultry, fish, dry beans, eggs \& nuts, a significantly greater percentage of participants consuming $\geq 2 \mathrm{MRs} /$ day met all other recommendations, followed by participants consuming 1 to $<2 \mathrm{MRs} /$ day and $<1 \mathrm{MR} /$ day, respectively ( $\mathrm{p}<$ 0.05). When participants in the MR categories using orlistat during months 7 to 12 were removed from the analyses, a significantly greater percentage of participants consuming $>2$ MRs/day met the same recommendations, followed by participants consuming 1 to $<2$ MRs/day and $<1 \mathrm{MR} /$ day, as the initial analyses (results of analyses not shown) $(\mathrm{p}<0.05)$.

\section{Discussion}

This study was the first investigation to assess diet quality and food group consumption for individuals with type 2 diabetes who were prescribed a reduced energy, low-fat, PMR plan. 
With the implementation of the PMR plan, ILI reported lower consumption of percent energy from fat, saturated fat and PUFA; trans fatty acids; and cholesterol, and greater consumption of fiber than DSE at 12 months. For intake from food groups from the FGP at 12 months, ILI reported a greater daily serving intake from the fruit; vegetable; and milk, yogurt \& cheese groups, and fewer daily serving intake from the fat, oils \& sweets group than DSE. Other measures of self-reported fat intake, frequency of consumption of low-fat versions of food, also indicated that ILI participants made greater reductions in fat intake than DSE at 12 months. This suggests enhancement in overall diet quality in ILI. As slightly over $20 \%$ of participants in ILI used orlistat during months 7 to 12 , this may have also contributed to fat intake differences between ILI and DSE.

At baseline, in regards to recommendations for percent energy from fat ( $\leq 30 \%)$ and saturated fat ( $\leq 10 \%$ ) intake, daily cholesterol consumption ( $\leq 300 \mathrm{mg} /$ day), and food group intake as provided from the 2000 Dietary Guidelines for Americans, ${ }^{2}$ most Look AHEAD participants' diets did not meet recommendations $(7 \%, 15 \%, 51 \%, 36 \%, 38 \%, 40 \%$, and $28 \%$ met the fat; saturated fat; cholesterol; and daily servings from the fruit; vegetable; milk, yogurt \& cheese; and fats, oils \& sweets group recommendations, respectively). ${ }^{14}$ At 12 months, a significantly greater percentage of ILI participants met recommendations for percent energy from fat and saturated fat; cholesterol; and daily servings from the fruit; vegetable; milk, yogurt \& cheese; and fats, oils \& sweets food groups $(29 \%, 51 \%, 80 \%$, $46 \%, 47 \%, 72 \%$, and $60 \%$, respectively) than DSE. Furthermore, when ILI participants were categorized by number of MRs consumed per day at 12 months, the greatest percentage of participants meeting dietary recommendations, excluding the recommendations for bread, cereal, rice \& pasta and meat, poultry, fish, dry beans, eggs \& nuts, were those consuming $\geq$ $2 \mathrm{MRs} /$ day, following by those consuming 1 to $<2 \mathrm{MR} /$ day and $<1 \mathrm{MR} /$ day, respectively. These results were consistent when participants in ILI using orlistat were removed from analyses. As most MRs were low in energy from fat, and beverage MRs contributed to the milk, yogurt \& cheese food group, greater consumption of MRs, and in particular beverage MRs, could have assisted ILI participants meet these recommendations.

The findings that consuming a reduced-energy, low-fat PMR plan is associated with improved diet quality is similar to what has been found in three other investigations that have examined changes in diet quality with a PMR plan in healthy overweight and obese participants. ${ }^{3-5}$ Similarly to this investigation, Miller found lower total and saturated fat intake with the PMR plan in comparison to an attention control comparison, ${ }^{3}$ while Tovar and colleagues found lower fat intake with the PMR plan in comparison to a reducedenergy, low-fat diet comprised of conventional foods. ${ }^{5}$ The present study, however, is the first to report on diet quality with a PMR plan in regards to food group consumption and in individuals with type 2 diabetes. It is important to note that ILI participants who report greater consumption of MRs also report greater minutes of moderate-intensity physical activity and attendance to intervention sessions. ${ }^{15}$ Thus in this investigation, greater consumption of MRs may be an indicator of engagement in healthy behaviors as a whole, which may include dietary choices that improve dietary quality.

In this investigation both ILI and DSE self-reported a decrease in energy intake of approximately $300 \mathrm{kcal} / \mathrm{day}$ from 0 to 12 months, but only ILI had a significant reduction in 
percent body weight. ${ }^{8}$ This difference in weight loss without a difference in energy intake between the two groups may reflect greater inaccuracies in reporting in the DSE group. The lack of a difference in self-reported energy intake in ILI vs. DSE, despite large differences in weight loss, may reflect the use of MRs and the training which ILI received in portion estimation and self-monitoring. As MRs have shown to produce better weight loss outcomes than prescribed hypocaloric diets of conventional foods, ${ }^{1}$ and a proposed reason for this is better portion control (i.e., MRs reduce the error in monitoring intake due to automatic portion control), ${ }^{16}$ the greater use of MRs by ILI might have increased accuracy of reporting energy intake than DSE at 12-months. Similarly, the ILI group was encouraged to weigh foods and accurately monitor portion sizes. Thus, the reported energy intake in the ILI group at 12 months may be more accurate than the DSE group. Finally, receiving nutrition education may also influence reporting of dietary intake, irrespective of behavior change, with reported intake more closely matching the education received. ${ }^{17}$ Thus, the reporting of a lower energy intake in the DSE group, without the occurrence of weight loss, may be a consequence of the nutrition education provided to DSE.

The similar findings between changes in energy intake in the two groups at 12-months, despite differences in weight loss outcomes, highlights the challenges of accurately assessing dietary intake with self-reported measures. While the U.S. Department of Agriculture 5-pass method, 24-hour dietary recall is considered to be the gold standard of dietary assessment, ${ }^{18,19}$ in large samples FFQs are usually used to assess dietary intake over a specified time period due to their low cost and ease of administration. ${ }^{20}$ Furthermore due to its self-report nature, it is recognized that under-reporting of dietary intake is fairly common, particularly in individuals who are overweight, ${ }^{21-24}$ have diabetes, ${ }^{24}$ and want to reduce their weight. ${ }^{22}$ While a version of this FFQ has been used previously and did show significant differences in energy intake across a 12-month period in randomized groups that received different dietary prescriptions, ${ }^{12}$ other research suggests that while self-reported energy intake from FFQs may contain errors, macronutrient reporting, particularly that adjusted for energy intake (i.e., percent energy from macronutrients or gram intake of macronutrients per $1000 \mathrm{kcal}$ ), may be less prone to reporting-error. ${ }^{25}$ This suggests that the findings of changes in relative intake of macronutrients may be more accurate than changes in absolute energy intake. As for food group intake, under-reporters general report consuming a greater amount of healthier foods (i.e., fruits and vegetables) and consuming fewer less healthy foods (i.e., pastries) than plausible reporters. ${ }^{26}$ Thus, while underreporting may have occurred in both groups, if there was greater under-reporting in DSE than ILI, diet quality of the DSE group may be lower than what is reported, suggesting an even greater difference in diet quality between the groups than what is described.

Strengths of the study include a large and racially- and ethnically-diverse sample, and the use of a valid and reliable FFQ designed to assess consumption of foods commonly eaten by the diverse sample. Limitations of the study relate to the self-reported nature of dietary assessment, and the lack of biomarkers to help validate dietary intake. The change in age eligibility after the first year of the investigation also produced a slightly younger sample, as compared to Look AHEAD participants not included in this investigation, from which the dietary assessments were conducted. The sample in this investigation also had a smaller percentage of African American participants and households with $<\$ 40,000$ annual income 
than Look AHEAD participants not included in this investigation. These demographic differences in this sample provide some indication of potential sampling bias from the overall Look AHEAD sample, which may influence outcomes. The impact of changes in physical activity on diet quality was also not able to be examined in this sample.

Additionally, a study design allowing comparisons between a reduced-energy, low-fat diet composed of conventional foods and a reduced-energy, low-fat, PMR plan would enhance understanding about how MR consumption itself affects diet quality.

\section{Conclusion and Application}

This investigation found after 12 months of following a reduced-energy, low-fat, PMR plan, a greater proportion of ILI participants were meeting overall dietary recommendations related to fat, cholesterol, and food group intake. Additionally, within ILI, a greater proportion of participants consuming $\geq 2 \mathrm{MRs} /$ day than $<1 \mathrm{MR} /$ day were meeting dietary recommendations. Thus, for individuals with type 2 diabetes for whom weight loss has been recommended, a PMR plan may assist with weight loss and improve overall diet quality.

\section{Acknowledgments}

\section{Funding and Support}

This study is supported by the Department of Health and Human Services through the following cooperative agreements from the National Institutes of Health: DK57136, DK57149, DK56990, DK57177, DK57171, DK57151, DK57182, DK57131, DK57002, DK57078, DK57154, DK57178, DK57219, DK57008, DK57135, and DK56992. The following federal agencies have contributed support: National Institute of Diabetes and Digestive and Kidney Diseases; National Heart, Lung, and Blood Institute; National Institute of Nursing Research; National Center on Minority Health and Health Disparities; NIH Office of Research on Women's Health; and the Centers for Disease Control and Prevention. This research was supported in part by the Intramural Research Program of the National Institute of Diabetes and Digestive and Kidney Diseases. The Indian Health Service (I.H.S.) provided personnel, medical oversight, and use of facilities. The opinions expressed in this paper are those of the authors and do not necessarily reflect the views of the I.H.S. or other funding sources.

Additional support was received from The Johns Hopkins Medical Institutions Bayview General Clinical Research Center (M01RR02719); the Massachusetts General Hospital Mallinckrodt General Clinical Research Center (M01RR01066); the University of Colorado Health Sciences Center General Clinical Research Center (M01RR00051) and Clinical Nutrition Research Unit (P30 DK48520); the University of Tennessee at Memphis General Clinical Research Center (M01RR0021140); the University of Pittsburgh General Clinical Research Center (M01RR000056 44) and NIH grant (DK 046204); the VA Puget Sound Health Care System Medical Research Service, Department of Veterans Affairs; and the Frederic C. Bartter General Clinical Research Center (M01RR01346).

The following organizations have committed to make major contributions to Look AHEAD: Federal Express; Health Management Resources; Johnson \& Johnson, LifeScan Inc.; Optifast-Novartis Nutrition; Roche Pharmaceuticals; Ross Product Division of Abbott Laboratories; Slim-Fast Foods Company; and Unilever.

\section{References}

1. Heymsfield SB, van Mierlo CA, van der Knaap HC, Heo M, Frier HI. Weight management using a meal replacement strategy: meta and pooling analysis from six studies. Int J Obes. 2003; 27:537549.

2. United States Department of Health and Human Services. Dietary Guidelines for Americans, 2005. 5. U.S. Government Printing Office; Washington, DC: 2000.

3. Miller GD. Improved nutrient intake in older obese adults undergoing a structured diet and exercise intentional weight loss program. J Nutr. 2010; 14:461-466. 
4. Ashley JM, Herzog H, Clodfelter S, Bovee V, Schrage J, Pritsos C. Nutrient adequacy during weight loss interventions: a randomized study in women comparing the dietary intake in a meal replacement group with a traditional food group. Nutr J. 2007; 6:12. [PubMed: 17592648]

5. Tovar AR, Caamaño MDC, Garcia-Padilla S, García OP, Duarte MA, Rosado JL. The inclusion of a partial meal replacement with or without inulin to a calorie restricted diet contributes to reach recommended intakes of micronutrients and decrease plasma triglycerides: a randomized clinical trial in obese Mexican women. Nutr J. 2012; 11:44. [PubMed: 22703579]

6. Wadden TA, West DS, Delahanty L, et al. The Look AHEAD Research Group. The Look AHEAD Study: a description of the lifestyle intervention and the evidence supporting it. Obesity. 2006; 14:737-752. [PubMed: 16855180]

7. Ryan DH, Espeland MA, Foster GD, et al. the Look AHEAD Research Group. Look AHEAD (Action for Health in Diabetes): design and methods for a clinical trial of weight loss for the prevention of cardiovascular disease in type 2 diabetes. Control Clin Trials. 2003; 24:610-628. [PubMed: 14500058]

8. The Look AHEAD Research Group. Reduction in weight and acrdiovascular disease risk factors in individuals with type 2 diabetes: one-year results of the Look AHEAD trial. Diabetes Care. 2007; 30:1374-1383. [PubMed: 17363746]

9. United States Department of Agriculture. Vol Home and Garden Bulletin Number 252. Washington, D.C: 1996. The food guide pyramid.

10. The Look AHEAD Research Group. [Accessed June 7, 2014] Look AHEAD: Action for Health in Diabetes. https://www.lookaheadtrial.org/public/home.cfm

11. Mayer-Davis EJ, Vitolins MZ, Carmichael SL, et al. Validity and reproducibility of a food frequency interveiw in a multi-cultural epidemiology study. Ann Epidemiol. 1999; 9:314-324. [PubMed: 10976858]

12. Mayer-Davis EJ, Sparks KC, Hirst K, et al. The Diabetes Prevention program Research Group. Dietary intake in the Diabetes Prevention Program cohort: baseline and 1-year post-randomization. Ann Epidemiol. 2004; 14:763-772. [PubMed: 15573453]

13. Block, G.; Hartman, AM. DIETSYS Version 3.0 User's Guide. Bethesda, MD: National Cancer Institute; 1994.

14. Vitolins MZ, Anderson AM, Delahanty LM, et al. the Look AHEAD Research Group. Action for Health in Diabetes (Look AHEAD) Trial: baseline evaluation of selected nutrients and food group intake. J Am Diet Assoc. 2009; 109:1367-1375. [PubMed: 19631042]

15. Wadden TA, West DS, Neiberg R, et al. One-year weight losses in the Look AHEAD Study: Factors associated with success. Obesity. 2009; 17:713-722. [PubMed: 19180071]

16. Wing RR, Jeffery RW. Food provision as a strategy to promote weight loss. Obes Res. 2001; 9(S5):S271-S275.

17. Kristal A, Andrilla CH, Koepsell TD, Diehr P, Cheadle A. Dietary assessment instruments are susceptible to intervention-associated response set bias. J Am Diet Assoc. 1998; 98:40-43. [PubMed: 9434649]

18. Subar AF, Kipnis V, Troiano RP, et al. Using intake biomarkers to evaluate the extent of dietary misreporting in a large sample of adults: the OPEN study. Am J Epidemiol. 2003; 158:1-13. [PubMed: 12835280]

19. Shai I, Rosner BA, Shahar DR, et al. Dietary evaluation and attenuation of relative risk: Multiple comparisons between blood and urinary biomarkers, food frequency, and 24-hour recall questionnaires: the DEARR Study. J Nutr. 2005; 135:573-579. [PubMed: 15735096]

20. Tooze JA, Subar AF, Thompson FE, Troiano R, Schatzkin A, Kipnis V. Psychosocial predictors of energy underreporting in a large doubly labeled water study. Am J Clin Nutr. 2004; 79:795-804. [PubMed: 15113717]

21. Bedard D, Shatenstien B, Nadon S. Underreporting of energy intake from a self-administered foodfrequency questionnaire completed by adults in Montreal. Public Health Nutrition. 2003; 7:675681. [PubMed: 15251058]

22. Johansson L, Solvoll K, Aa Bjorneboe GE, Drevon CA. Under- and overreporting of energy intake related to weight status and lifestyle in a nationwide sample. Am J Clin Nutr. 1998; 68:266-274. [PubMed: 9701182] 
23. Olafsdottir AS, Thorsdottir I, Gunnarsdottir I, Thorgeirsdottir H, Steingrimsdottir L. Comparison of women's diet assessed by FFQs and 24-hour recalls with and without underreporters: associations and biomarkers. Ann Nutr Metab. 2006; 50:450-460. [PubMed: 16877864]

24. Yannakoulia M, Panagiotakos DB, Pitsavos C, et al. Low energy reporting related to lifestyle, clinical, and pychosocial factors in a randomly selected population sample of Greek adults: the ATTICA study. J Am Coll Nutr. 2007; 26:327-333. [PubMed: 17906184]

25. Voss S, Kroke A, Klipstein-Grobusch K, Boeing H. Is macronutrient composition of dietary intake data affected by underreporting? Results from the EPIC-Potsdam Study. Euro J Clin Nutr. 1998; 52:119-126.

26. Mendez MA, Popkin BM, Buckland G, et al. Alternative methods of accounting for underreporting and overreporting when measuring dietary intake-obesity relations. Am J Epidemiol. 2011; 173:448-458. [PubMed: 21242302]

\section{Appendix}

This report represents a further analysis of the first year weight losses in the Look AHEAD study. It was prepared by the authors on behalf of the Look AHEAD Research Group. Members of the research group who participated in the recruitment, assessment, treatment, and retention of participants during the first year of the study are shown below:

\section{Clinical Sites}

The Johns Hopkins Medical Institutions Frederick L. Brancati, MD, MHS ${ }^{1}$; Jeff Honas, $\mathrm{MS}^{2}$; Lawrence Cheskin, $\mathrm{MD}^{3}$; Jeanne M. Clark, MD, MPH${ }^{3}$; Kerry Stewart, EdD ${ }^{3}$; Richard Rubin, $\mathrm{PhD}^{3}$; Jeanne Charleston, RN; Kathy Horak, RD.

Pennington Biomedical Research Center George A. Bray, $\mathrm{MD}^{1}$; Kristi Rau ${ }^{2}$; Allison Strate, $\mathrm{RN}^{2}$; Brandi Armand, $\mathrm{LPN}^{2}$; Frank L. Greenway, $\mathrm{MD}^{3}$; Donna H. Ryan, $\mathrm{MD}^{3}$; Donald Williamson, $\mathrm{PhD}^{3}$; Amy Bachand; Michelle Begnaud; Betsy Berhard; Elizabeth Caderette; Barbara Cerniauskas; David Creel; Diane Crow; Helen Guay; Nancy Kora; Kelly LaFleur; Kim Landry; Missy Lingle; Jennifer Perault; Mandy Shipp, RD; Marisa Smith; Elizabeth Tucker.

The University of Alabama at Birmingham Cora E. Lewis, MD, MSPH ${ }^{1}$; Sheikilya Thomas $\mathrm{MPH}^{2}$; Monika Safford, MD ${ }^{3}$; Vicki DiLillo, PhD; Charlotte Bragg, MS, RD, LD; Amy Dobelstein; Stacey Gilbert, MPH; Stephen Glasser, MD; Sara Hannum, MA; Anne Hubbell, MS; Jennifer Jones, MA; DeLavallade Lee; Ruth Luketic, MA, MBA, MPH; Karen Marshall; L. Christie Oden; Janet Raines, MS; Cathy Roche, RN, BSN; Janet Truman; Nita Webb, MA; Audrey Wrenn, MAEd.

Harvard Center Massachusetts General Hospital: David M. Nathan, MD ${ }^{1}$; Heather Turgeon, RN, BS, $\mathrm{CDE}^{2}$; Kristina Schumann, $\mathrm{BA}^{2}$; Enrico Cagliero, $\mathrm{MD}^{3}$; Linda Delahanty, MS, $\mathrm{RD}^{3}$; Kathryn Hayward, MD ${ }^{3}$; Ellen Anderson, MS, RD ${ }^{3}$; Laurie Bissett, MS, RD; Richard Ginsburg, PhD; Valerie Goldman, MS, RD; Virginia Harlan, MSW; Charles McKitrick, RN, BSN, CDE; Alan McNamara, BS; Theresa Michel, DPT, DSc CCS; Alexi Poulos, BA;

${ }_{2}^{1}$ Principal Investigator

${ }_{3}^{2}$ Program Coordinator

${ }^{3}$ Co-Investigator 
Barbara Steiner, EdM; Joclyn Tosch, BA. Joslin Diabetes Center: Edward S. Horton, MD ${ }^{1}$; Sharon D. Jackson, MS, RD, $\mathrm{CDE}^{2}$; Osama Hamdy, $\mathrm{MD}, \mathrm{PhD}^{3}$; A. Enrique Caballero, $\mathrm{MD}^{3}$; Sarah Bain, BS; Elizabeth Bovaird, BSN, RN; Ann Goebel-Fabbri, PhD; Lori Lambert, MS, RD; Sarah Ledbury, MEd, RD; Maureen Malloy, BS; Kerry Ovalle, MS, RCEP, CDE. Beth Israel Deaconess Medical Center: George Blackburn, MD, $\mathrm{PhD}^{1}$; Christos Mantzoros, MD, DSc ${ }^{3}$; Kristinia Day, RD; Ann McNamara, RN.

University of Colorado Health Sciences Center James O. Hill, $\mathrm{PhD}^{1}$; Marsha Miller, MS, $\mathrm{RD}^{2}$; JoAnn Phillipp, $\mathrm{MS}^{2}$; Robert Schwartz, $\mathrm{MD}^{3}$; Brent Van Dorsten, $\mathrm{PhD}^{3}$; Judith Regensteiner, $\mathrm{PhD}^{3}$; Salma Benchekroun MS; Ligia Coelho, BS; Paulette Cohrs, RN, BSN; Elizabeth Daeninck, MS, RD; Amy Fields, MPH; Susan Green; April Hamilton, BS, CCRC; Jere Hamilton, BA; Eugene Leshchinskiy; Michael McDermott, MD; Lindsey Munkwitz, BS; Loretta Rome, TRS; Kristin Wallace, MPH; Terra Worley, BA.

Baylor College of Medicine John P. Foreyt, $\mathrm{PhD}^{1}$; Rebecca S. Reeves, DrPH, RD ${ }^{2}$; Henry Pownall, $\mathrm{PhD}^{3}$; Ashok Balasubramanyam, $\mathrm{MBBS}^{3}$; Peter Jones, $\mathrm{MD}^{3}$; Michele Burrington, RD; Chu-Huang Chen, MD, PhD ${ }^{3}$; Allyson Clark, RD; Molly Gee, MEd, RD; Sharon Griggs; Michelle Hamilton; Veronica Holley; Jayne Joseph, RD; Patricia Pace, RD: Julieta Palencia, RN; Olga Satterwhite, RD; Jennifer Schmidt; Devin Volding, LMSW; Carolyn White.

University of California at Los Angeles School of Medicine Mohammed F. Saad, MD ${ }^{1}$; Siran Ghazarian, $\mathrm{MD}^{2}$; Ken C. Chiu, MD ${ }^{3}$; Medhat Botrous; Michelle Chan, BS; Kati Konersman, MA, RD, CDE; Magpuri Perpetua, RD.

The University of Tennessee Health Science Center University of Tennessee East. Karen C. Johnson, MD, MPH ${ }^{1}$; Carolyn Gresham, $\mathrm{RN}^{2}$; Stephanie Connelly, MD, $\mathrm{MPH}^{3}$; Amy Brewer, RD, MS; Mace Coday, PhD; Lisa Jones, RN; Lynne Lichtermann, RN, BSN; Shirley Vosburg, RD, MPH; and J. Lee Taylor, MEd, MBA. University of Tennessee Downtown. Abbas E. Kitabchi, PhD, MD ${ }^{1}$; Helen Lambeth, RN, BSN ${ }^{2}$; Debra Clark, LPN; Andrea Crisler, MT; Gracie Cunningham; Donna Green, RN; Debra Force, MS, RD, LDN; Robert Kores, PhD; Renate Rosenthal PhD; Elizabeth Smith, MS, RD, LDN; and Maria Sun, MS, RD, LDN; and Judith Soberman, $\mathrm{MD}^{3}$.

University of Minnesota Robert W. Jeffery, $\mathrm{PhD}^{1}$; Carolyn Thorson, CCRP 2 ; John P. Bantle, $\mathrm{MD}^{3}$; J. Bruce Redmon, $\mathrm{MD}^{3}$; Richard S. Crow, $\mathrm{MD}^{3}$; Scott Crow, $\mathrm{MD}^{3}$; Susan K Raatz, PhD, RD ${ }^{3}$; Kerrin Brelje, MPH, RD; Carolyne Campbell; Jeanne Carls, MEd; Tara Carmean-Mihm, BA; Emily Finch, MA; Anna Fox, MA; Elizabeth Hoelscher, MPH, RD, CHES; La Donna James; Vicki A. Maddy, BS, RD; Therese Ockenden, RN; Birgitta I. Rice, MS, RPh CHES; Tricia Skarphol, BS; Ann D. Tucker, BA; Mary Susan Voeller, BA; Cara Walcheck, BS, RD.

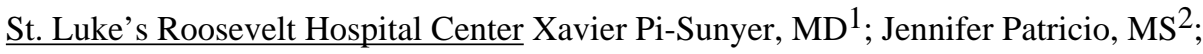
Stanley Heshka, $\mathrm{PhD}^{3}$; Carmen Pal, $\mathrm{MD}^{3}$; Lynn Allen, MD; Diane Hirsch, RNC, MS, CDE; Mary Anne Holowaty, MS, CN. 
University of Pennsylvania Thomas A. Wadden, $\mathrm{PhD}^{1}$; Barbara J. Maschak-Carey, MSN, $\mathrm{CDE}^{2}$; Stanley Schwartz, $\mathrm{MD}^{3}$; Gary D. Foster, $\mathrm{PhD}^{3}$; Robert I. Berkowitz, $\mathrm{MD}^{3}$; Henry Glick, $\mathrm{PhD}^{3}$; Shiriki K. Kumanyika, PhD, RD, MPH ${ }^{3}$; Johanna Brock; Helen Chomentowski; Vicki Clark; Canice Crerand, PhD; Renee Davenport; Andrea Diamond, MS, RD; Anthony Fabricatore, PhD; Louise Hesson, MSN; Stephanie Krauthamer-Ewing, MPH; Robert Kuehnel, PhD; Patricia Lipschutz, MSN; Monica Mullen, MS, RD; Leslie Womble, PhD, MS; Nayyar Iqbal, MD.

University of Pittsburgh David E. Kelley, $\mathrm{MD}^{1}$; Jacqueline Wesche-Thobaben, RN, BSN, $\mathrm{CDE}^{2}$; Lewis Kuller, $\mathrm{MD}$, DrPH ${ }^{3}$; Andrea Kriska, $\mathrm{PhD}^{3}$; Janet Bonk, RN, MPH; Rebecca Danchenko, BS; Daniel Edmundowicz, MD ${ }^{3}$; Mary L. Klem, PhD, MLIS ${ }^{3}$; Monica E. Yamamoto, DrPH, RD, FADA ${ }^{3}$; Barb Elnyczky, MA; George A. Grove, MS; Pat Harper, MS, RD, LDN; Janet Krulia, RN, BSN, CDE; Juliet Mancino, MS, RD, CDE, LDN; Anne Mathews, MS, RD, LDN; Tracey Y. Murray, BS; Joan R. Ritchea; Jennifer Rush, MPH; Karen Vujevich, RN-BC, MSN, CRNP; Donna Wolf, MS.

The Miriam Hospital/Brown Medical School Rena R. Wing, $\mathrm{PhD}^{1}$; Renee Bright, $\mathrm{MS}^{2}$; Vincent Pera, $\mathrm{MD}^{3}$; John Jakicic, $\mathrm{PhD}^{3}$; Deborah Tate, $\mathrm{PhD}^{3}$; Amy Gorin, $\mathrm{PhD}^{3}$; Kara Gallagher, $\mathrm{PhD}^{3}$; Amy Bach, PhD; Barbara Bancroft, RN, MS; Anna Bertorelli, MBA, RD; Richard Carey, BS; Tatum Charron, BS; Heather Chenot, MS; Kimberley Chula-Maguire, MS; Pamela Coward, MS, RD; Lisa Cronkite, BS; Julie Currin, MD; Maureen Daly, RN; Caitlin Egan, MS; Erica Ferguson, BS, RD; Linda Foss, MPH; Jennifer Gauvin, BS; Don Kieffer, PhD; Lauren Lessard, BS; Deborah Maier, MS; JP Massaro, BS; Tammy Monk, MS; Rob Nicholson, PhD; Erin Patterson, BS; Suzanne Phelan, PhD; Hollie Raynor, PhD, RD; Douglas Raynor, PhD; Natalie Robinson, MS, RD; Deborah Robles; Jane Tavares, BS.

The University of Texas Health Science Center at San Antonio Steven M. Haffner, MD ${ }^{1}$; Maria G. Montez, RN, MSHP, $\mathrm{CDE}^{2}$; Carlos Lorenzo, $\mathrm{MD}^{3}$.

University of Washington/VA Puget Sound Health Care System Steven E. Kahn, MB, $\mathrm{ChB}^{1}$; Brenda Montgomery, RN, MS, $\mathrm{CDE}^{2}$; Robert Knopp, $\mathrm{MD}^{3}$; Edward Lipkin, $\mathrm{MD}^{3}$; Matthew L. Maciejewski, $\mathrm{PhD}^{3}$; Dace Trence, $\mathrm{MD}^{3}$; Terry Barrett, BS; Joli Bartell, BA; Diane Greenberg, PhD; Anne Murillo, BS; Betty Ann Richmond, MEd; April Thomas, MPH, RD.

Southwestern American Indian Center, Phoenix, Arizona and Shiprock, New Mexico William C. Knowler, MD, DrPH ${ }^{1}$; Paula Bolin, RN, $\mathrm{MC}^{2}$; Tina Killean, $\mathrm{BS}^{2}$; Cathy Manus, LPN $^{3}$; Jonathan Krakoff, MD ${ }^{3}$; Jeffrey M. Curtis, MD, MPH ${ }^{3}$; Justin Glass, MD $^{3}$; Sara Michaels, $\mathrm{MD}^{3}$; Peter H. Bennett, MB, FRCP ${ }^{3}$; Tina Morgan ${ }^{3}$; Shandiin Begay, MPH; Bernadita Fallis RN, RHIT, CCS; Jeanette Hermes, MS, RD; Diane F. Hollowbreast; Ruby Johnson; Maria Meacham, BSN, RN, CDE; Julie Nelson, RD; Carol Percy, RN; Patricia Poorthunder; Sandra Sangster; Nancy Scurlock, MSN, ANP-C, CDE; Leigh A. Shovestull, RD, CDE; Janelia Smiley; Katie Toledo, MS, LPC; Christina Tomchee, BA; Darryl Tonemah PhD. 
University of Southern California Anne Peters, MD ${ }^{1}$; Valerie Ruelas, MSW, LCSW ${ }^{2}$; Siran Ghazarian Sengardi, MD²; Kathryn Graves, MPH, RD, CDE; Kati Konersman, MA, RD, CDE; Sara Serafin-Dokhan.

\section{Coordinating Center}

Wake Forest University Mark A. Espeland, $\mathrm{PhD}^{1}$; Judy L. Bahnson, BA ${ }^{2}$; Lynne Wagenknecht, DrPH ${ }^{3}$; David Reboussin, $\mathrm{PhD}^{3}$; W. Jack Rejeski, $\mathrm{PhD}^{3}$; Alain Bertoni, MD, $\mathrm{MPH}^{3}$; Wei Lang, $\mathrm{PhD}^{3}$; Gary Miller, $\mathrm{PhD}^{3}$; David Lefkowitz, $\mathrm{MD}^{3}$; Patrick S. Reynolds, $\mathrm{MD}^{3}$; Paul Ribisl, $\mathrm{PhD}^{3}$; Mara Vitolins, DrPH ${ }^{3}$; Michael Booth, $\mathrm{MBA}^{2}$; Kathy M. Dotson, $\mathrm{BA}^{2}$; Amelia Hodges, $\mathrm{BS}^{2}$; Carrie C. Williams, MA² Jerry M. Barnes, MA; Patricia A. Feeney, MS; Jason Griffin, BS; Lea Harvin, BS; William Herman, MD, MPH; Patricia Hogan, MS; Sarah Jaramillo, MS; Mark King, BS; Kathy Lane, BS; Rebecca Neiberg, MS; Andrea Ruggiero, MS; Christian Speas, BS; Michael P. Walkup, MS; Karen Wall; Michelle Ward; Delia S. West, PhD; Terri Windham.

\section{Central Resources Centers}

DXA Reading Center, University of California at San Francisco Michael Nevitt, $\mathrm{PhD}^{1}$; Susan Ewing, MS; Cynthia Hayashi; Jason Maeda, MPH; Lisa Palermo, MS, MA; Michaela Rahorst; Ann Schwartz, PhD; John Shepherd, PhD.

Central Laboratory, Northwest Lipid Research Laboratories Santica M. Marcovina, PhD, $\mathrm{ScD}^{1}$; Greg Strylewicz, MS.

ECG Reading Center, EPICARE, Wake Forest University School of Medicine Ronald J. Prineas, $\mathrm{MD}, \mathrm{PhD}^{1}$; Teresa Alexander; Lisa Billings; Charles Campbell, AAS, BS; Sharon Hall; Susan Hensley; Yabing Li, MD; Zhu-Ming Zhang, MD.

Diet Assessment Center, University of South Carolina, Arnold School of Public Health, Center for Research in Nutrition and Health Disparities Elizabeth J Mayer-Davis, $\mathrm{PhD}^{1}$; Robert Moran, PhD.

$\underline{\text { Hall-Foushee Communications, Inc. }}$

Richard Foushee, PhD; Nancy J. Hall, MA.

\section{Federal Sponsors}

National Institute of Diabetes and Digestive and Kidney Diseases: Barbara Harrison, MS; Van S. Hubbard, MD PhD; Susan Z. Yanovski, MD.

National Heart, Lung, and Blood Institute: Lawton S. Cooper, MD, MPH; Jeffrey Cutler, MD, MPH; Eva Obarzanek, PhD, MPH, RD.

Centers for Disease Control and Prevention: Edward W. Gregg, PhD; David F. Williamson, $\mathrm{PhD}$; Ping Zhang, PhD. 


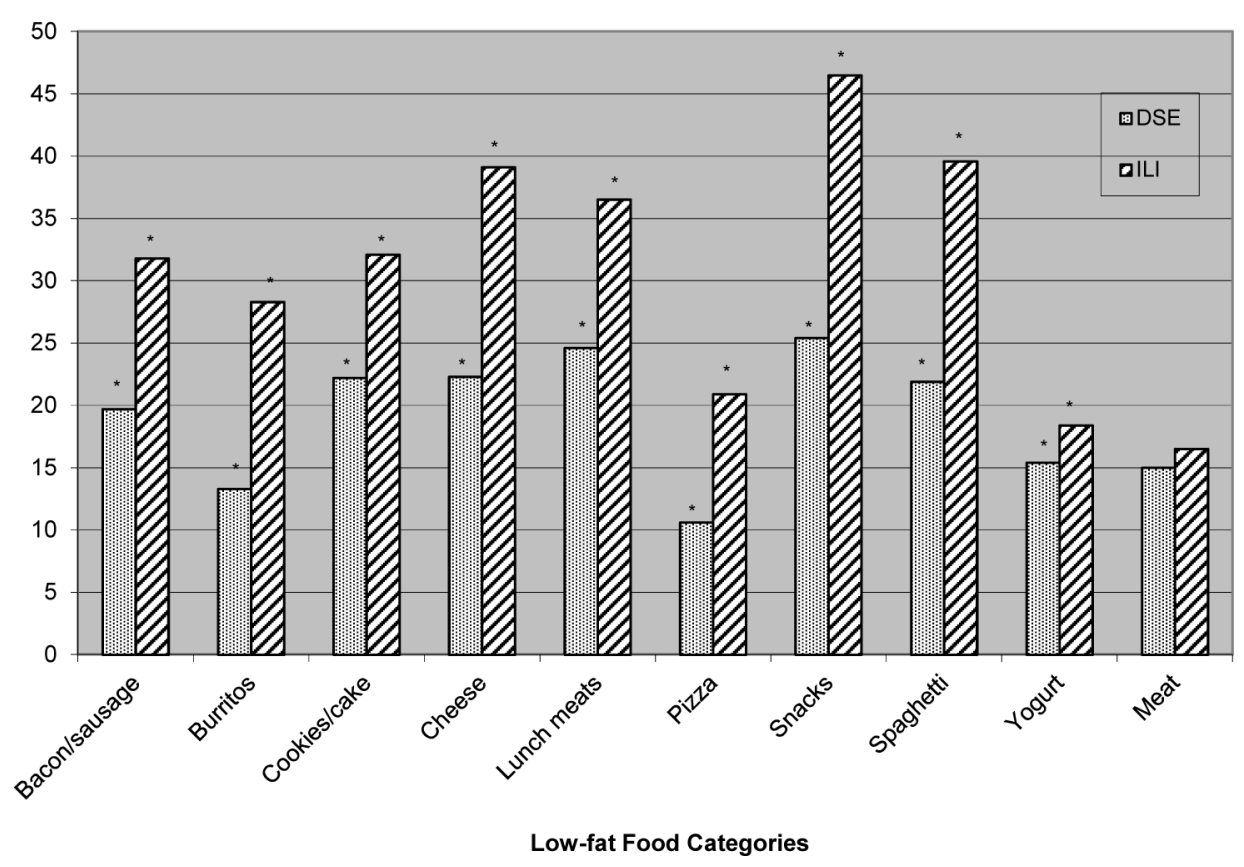

Figure 1.

Percentage of participants increasing consumption of low-fat food items from 0- to 12month in the Diabetes Support and Education (DSE) and Intensive Lifestyle Intervention (ILI) conditions. * $\mathrm{P}<0.05$. 


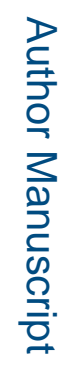

D

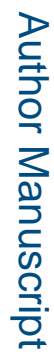

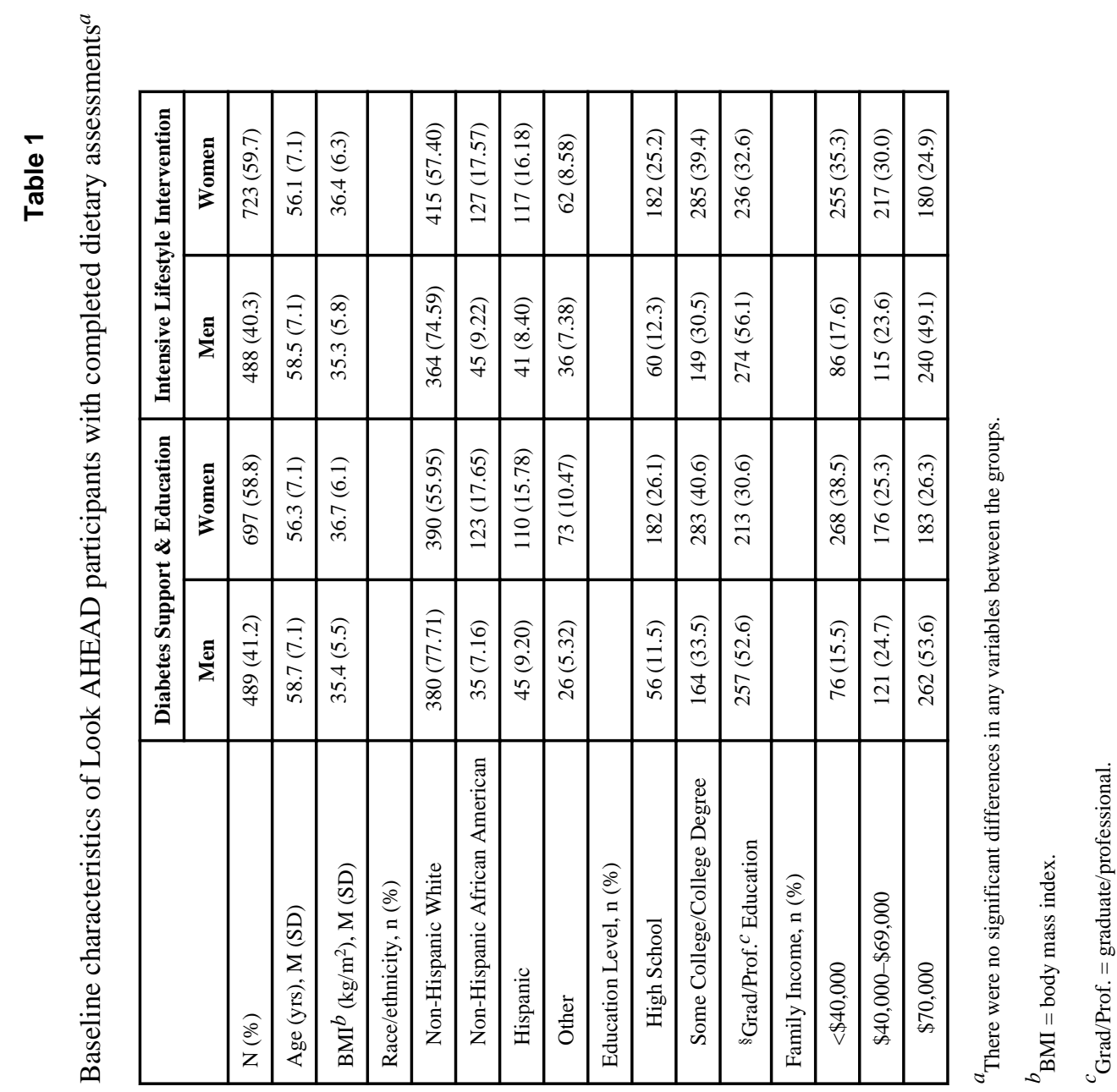

J Acad Nutr Diet. Author manuscript; available in PMC 2016 May 01. 


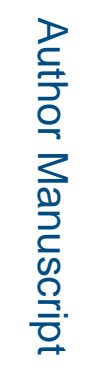

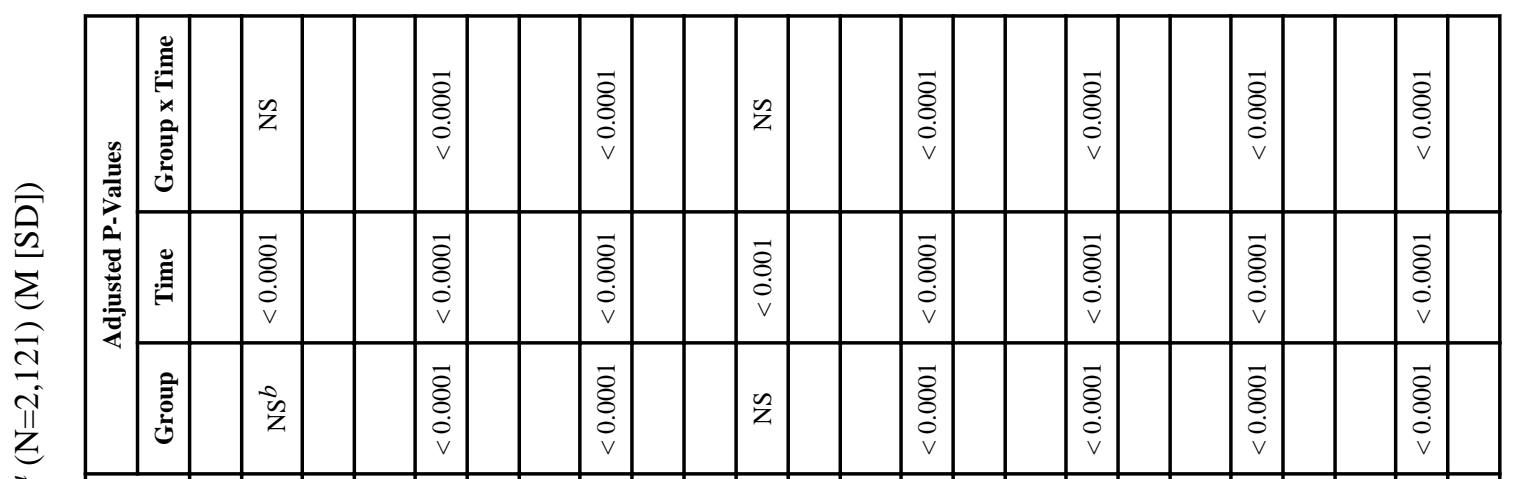

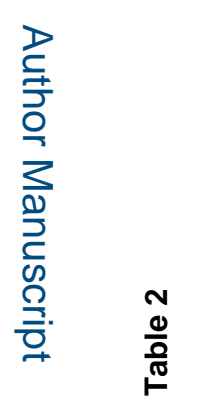

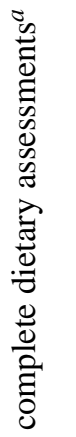

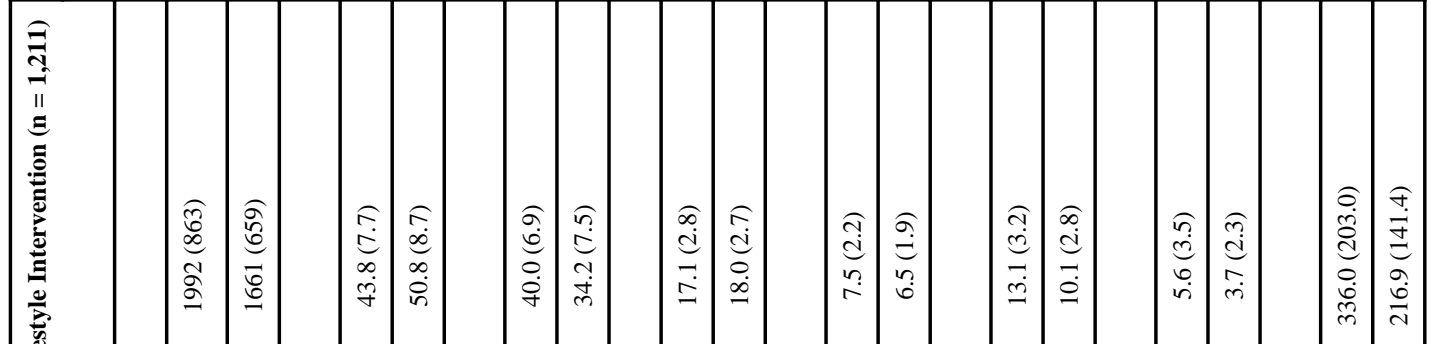

五

政

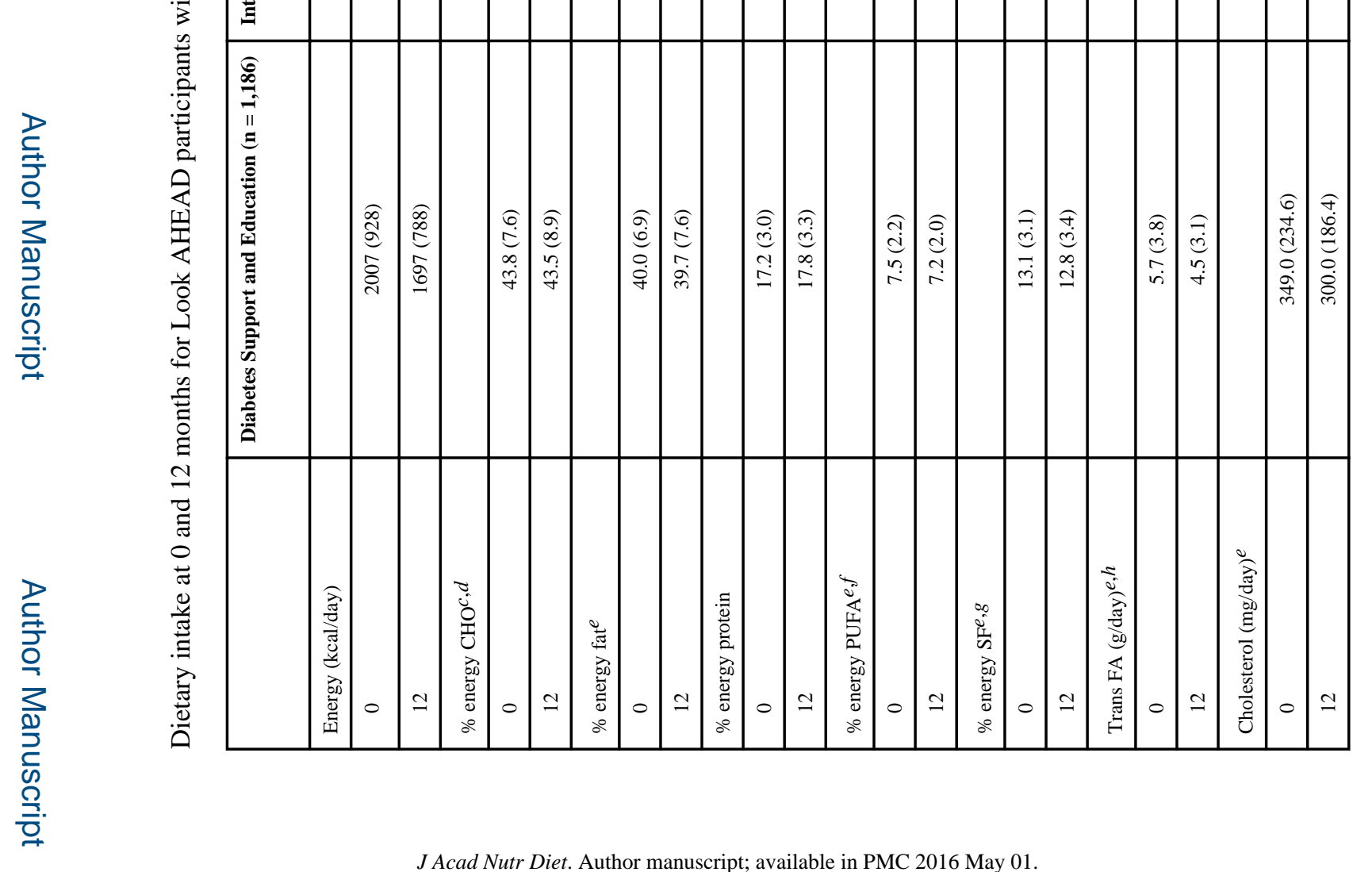




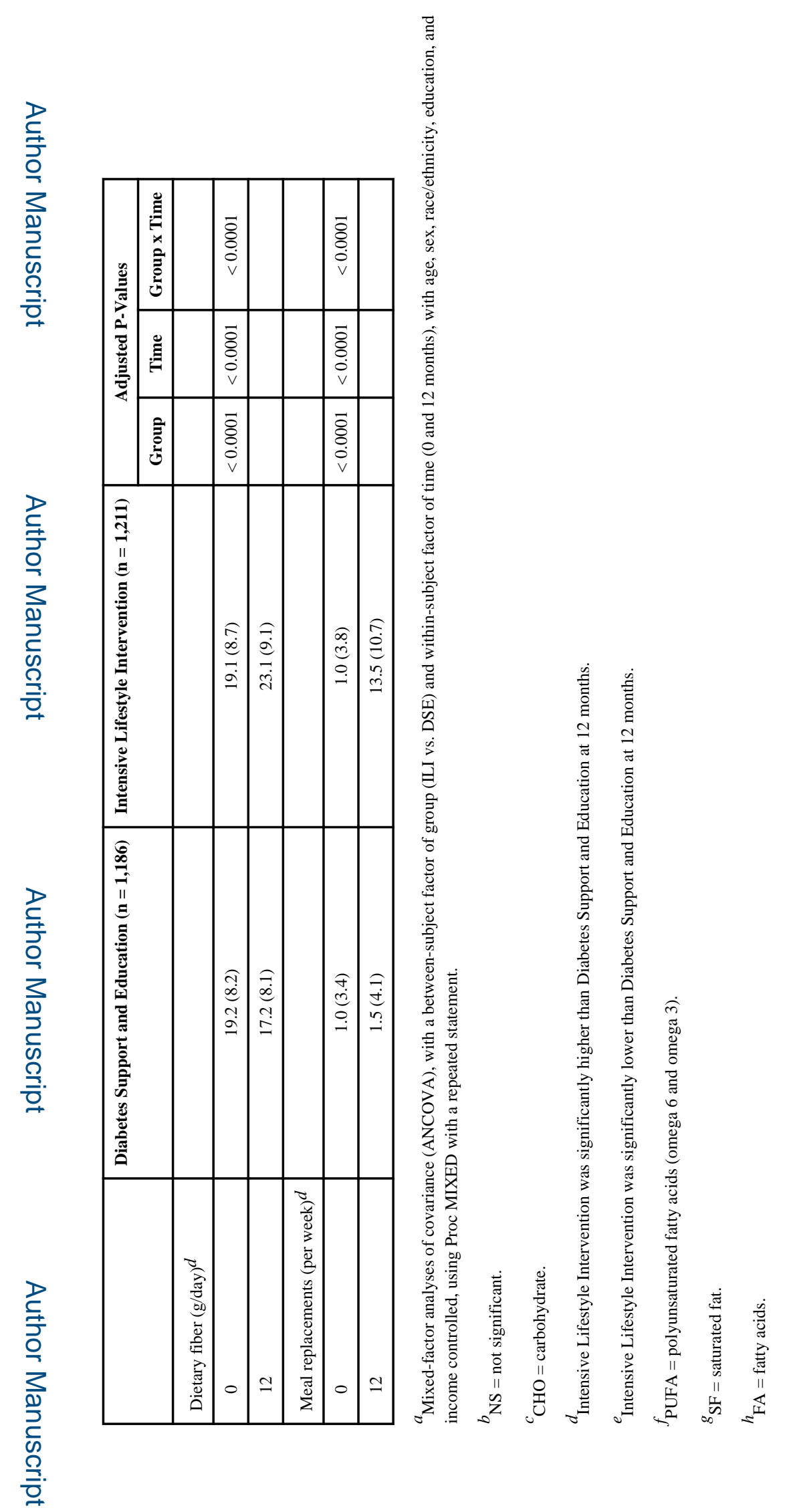

J Acad Nutr Diet. Author manuscript; available in PMC 2016 May 01. 

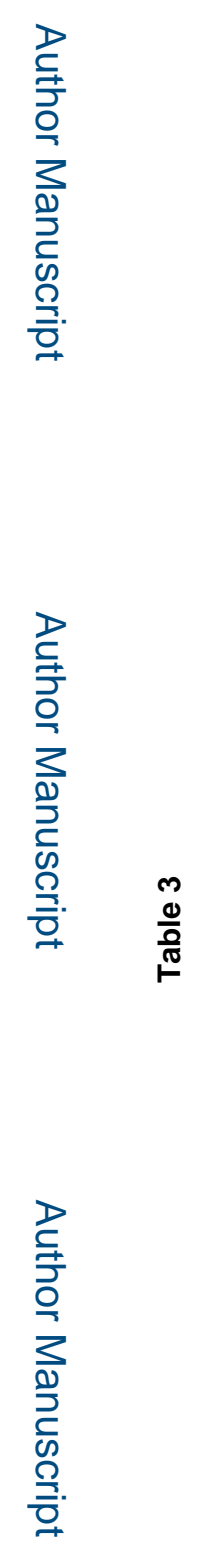

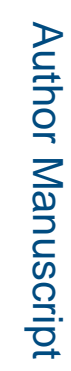

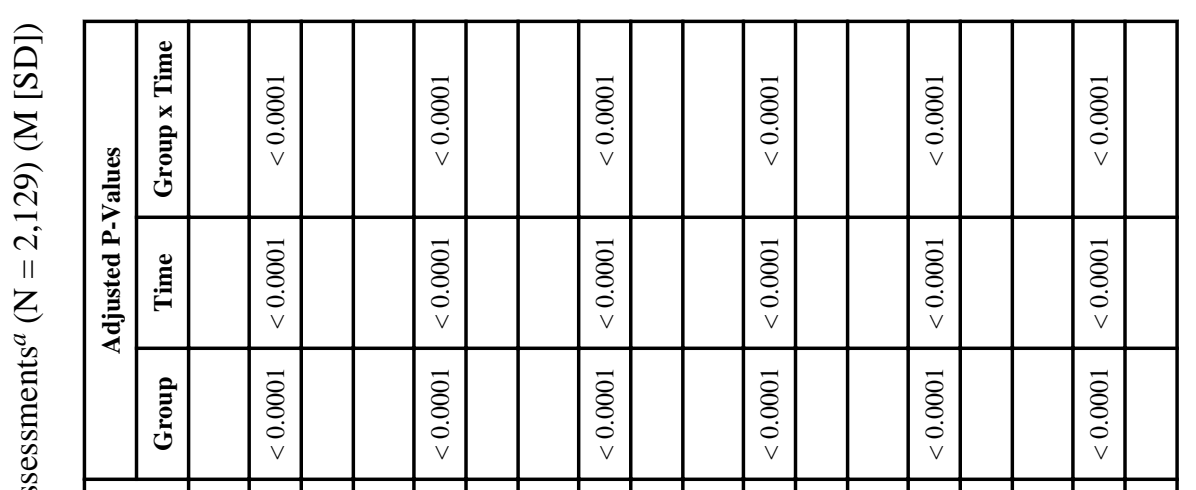




\section{Table 4}

Percentage of Look AHEAD participants with complete dietary assessments who met the dietary recommendations at 12 months $(\mathrm{N}=2,397)$

\begin{tabular}{|l|c|c|c|c|}
\hline Nutrient & Recommendation & $\begin{array}{c}\text { Diabetes Support \& } \\
\text { Education (n = 1,186) }\end{array}$ & $\begin{array}{c}\text { Intensive Lifestyle } \\
\text { Intervention (n = 1,211) }\end{array}$ & P-value $^{\boldsymbol{a}}$ \\
\hline$\%$ energy from fat & $\leq 30 \%$ & 9.4 & 28.9 & $<0.0001$ \\
\hline$\%$ energy from saturated fat & $\leq 10 \%$ & 19.1 & 50.6 & $<0.0001$ \\
\hline Cholesterol & $\leq 300 \mathrm{mg} /$ day & 60.3 & 79.9 & $<0.0001$ \\
\hline Bread, cereal, rice \& pasta & $\geq 6$ servings/day & 2.4 & 1.2 & $<0.05$ \\
\hline Fruit & $\geq 2$ servings/day & 36.2 & 45.5 & $<0.0001$ \\
\hline Vegetable & $\geq 3$ servings/day & 37.4 & 47.4 & $<0.0001$ \\
\hline Milk, yogurt \& cheese & $\geq 2$ servings/day & 35.1 & 72.4 & $<0.0001$ \\
\hline Meat, poultry, fish, dry beans, eggs \& nuts & $\geq 2$ servings/day & 54.1 & 36.3 & $<0.0001$ \\
\hline Fats, oils \& sweets & Limit, $\leq 1$ serving/day & 37.7 & 59.5 & $<0.0001$ \\
\hline
\end{tabular}

$a_{\text {P-values are for unadjusted Chi-square tests. }}$ 


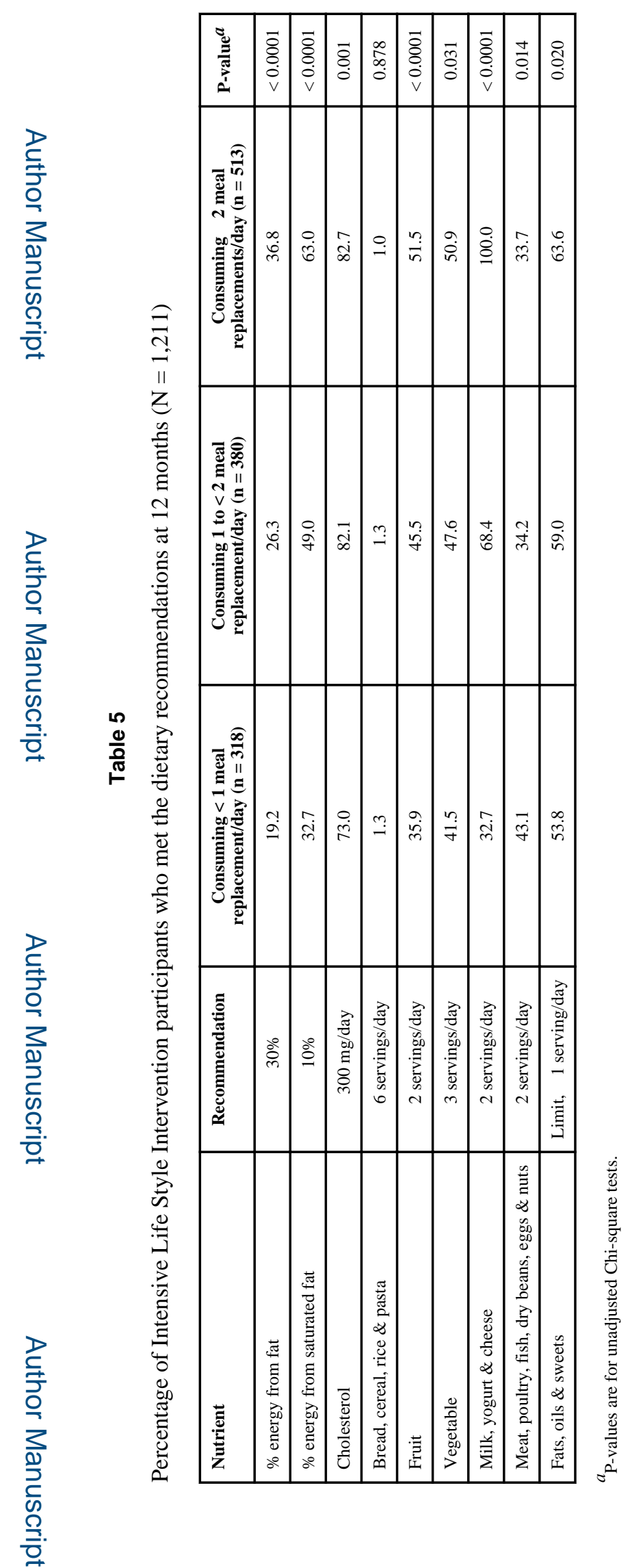

J Acad Nutr Diet. Author manuscript; available in PMC 2016 May 01. 